\title{
Uma Experiência de Pesquisa com as Crianças: Escuta, Participação e Proteção
}

\author{
Una Experiencia de Pesquisa con los Niños: Escucha, Participación y \\ Protección
}

\author{
A Research Experiment with Children: Listening, Participation and \\ Protection
}

Eleonora das Neves Simões ${ }^{1}$

\begin{abstract}
Resumo
A proposta deste trabalho é analisar os movimentos e decisões com relação aos aspectos metodológicos de uma pesquisa de Mestrado, nas interfaces com o referencial teórico. A investigação foi realizada em uma escola pública de Educação Infantil, localizada na região metropolitana de Porto Alegre com crianças de quatro e cinco anos e tinha como objetivo analisar os processos de participação das crianças na produção e transformação dos espaços da escola. A partir daí, a temática a ser desenvolvida neste texto trata da relação indissociável entre a base teórica e os métodos de pesquisa, dando destaque para três questões: a escuta das necessidades das crianças no processo de pesquisa; a participação das crianças como um direito e como parte de uma posição política de considerá-las como atores sociais; e também, sobre a proteção, ou seja, sobre os direitos à imagem, a identificação e o esforço necessário em dimensionar o cuidado e a ética na pesquisa com crianças na relação com o direito a participação. Na parte final, destaca-se a possibilidade de uma pesquisa produzida no encontro com as crianças, não tomada como definida a priori e afastando-se da ideia de verificação de hipóteses, apontando assim como as decisões com relação aos métodos de aproximação e de produção de dados, são produzidos a partir de um modo de perceber as crianças. Neste caso, como potentes na sua relação com o mundo.
\end{abstract}

Palavras-Chave: metodologia de pesquisa; participação das crianças; pesquisa com crianças

\section{Resumen}

La propuesta de este trabajo es analizar los movimientos y decisiones con relación a los aspectos metodológicos de una pesquisa de Maestría, en las interfaces con el referencial teórico. La investigación fue realizada en una escuela pública de Educación Infantil, localizada en la región metropolitana de Porto Alegre con niños de cuatro y cinco años y tenía como objetivo analizar los procesos de participación de los niños en la producción y transformación de los espacios de la escuela. A partir de ahí, la temática a ser desarrollada en este texto trata de la relación indisociable entre la base teórica y los métodos de pesquisa, dando destaque para tres cuestiones: la escucha de las necesidades de los niños en el proceso de pesquisa; la participación de los niños como un derecho y como parte de una posición política de considerarlas como actores sociales; y también, sobre la protección, esto es, sobre los derechos a la imagen, la identificación y el esfuerzo necesario en dimensionar el cuidado y la ética en la pesquisa con niños en la relación con el derecho a participación. En la parte final, se sobresale la posibilidad de una pesquisa hecha en el encuentro con los niños, no tomada como definida a priori y alejándose de la idea de verificación de hipótesis, apuntando así como las decisiones con relación a los métodos de aproximación y de producción de datos son hechos a partir de un modo de percibir los niños. En este caso, como potentes en su relación con el mundo.

Palabras claves: pesquisa con niños; metodología de pesquisa; participación de los niños

\footnotetext{
${ }^{1}$ Mestre em Educação; Universidade Federal de Pelotas; Pelotas, Rio Grande do Sul e Brasil; nora_simoes@hotmail.com
} 


\begin{abstract}
The purpose of this work is to analyze the moves and decisions regarding the methodological aspects of a Master's Program research, at the interface of the theoretical reference. The research was carried out in a public school of Early Childhood Education, located in the metropolitan region of Porto Alegre with children aged 4-5. Furthermore, it aims to analyze the processes of children's participation in the production of space and school transformation process. Henceforth, the subject-matter in this text addresses the inextricable relationship between theoretical foundations and research methods, highlighting three issues: listening to children's needs in the research process; children's participation as a right and as part of a political position to consider them as social actors. In addition, regarding protection, i.e., image rigths, the identification and the effort required to dimension the care and the ethics in the research with children concerning the right to participation. In the final analysis, we highlight the possibility of a research produced while meeting with the children, not taken as defined a priori and moving away from the idea of hypothesis verification method, thus pointing out how the decisions regarding the methods of approach and data production are originated from the way of perceiving children. In this case, as powerful children viewing the world around them.
\end{abstract}

Keywords: children's participation; research methodology; research with children.

\title{
1. Introdução
}

Esta escrita tem como intento traçar uma analítica das congruências entre a percepção de um modo de fazer pesquisa com crianças, e entre o modo de percebê-las como potentes na sua relação com o mundo. Partindo das decisões metodológicas realizadas em uma pesquisa de Mestrado, que se intitulou De mãos dadas com as crianças pequenas pelos espaços da escola: interações, brincadeiras e invenções ${ }^{2}$ (SIMÕES, 2015), traço assim uma discussão que traz para o debate modos de colocar as crianças como sujeitos das investigações, ao invés de objetos.

Assim, aqui especificamente abordo as questões de escuta, participação e proteção. Ou seja, abordo como em minha prática de investigação, dimensionei os cuidados éticos com a participação das crianças. Destaco como esse modo de fazer pesquisa esteve entrelaçado com o referencial teórico que dá sustento as análises desenvolvidas ao longo da dissertação. Trago então para o corpo do texto questões sobre o consentimento, o uso de imagens, a escolha dos nomes de identificação - como parte deste processo de proteção -, e a fotografia e o caderno de campo - como parte dos processos de escuta e participação.

A pesquisa a que me refiro, foi realizada em uma escola municipal de Educação Infantil, localizada em uma cidade da região metropolitana de Porto Alegre, com um grupo de crianças que tinham entre quatro e cinco anos de idade. Esta teve um caráter etnográfico que lança olhar para a prática social na escola (ANDRÉ, 2008; GRAUE; WALSH, 2003). Foram utilizadas as fotografias (das crianças e da pesquisadora) e o caderno de campo como

\footnotetext{
${ }^{2}$ Esta investigação contou com o apoio do CNPQ, através de uma bolsa de estudos.
} 
estratégia de produção de dados, mas também de aproximação, registro e compreensão do campo.

Como estratégia de organização do texto, nesta introdução tratei de situar a leitura sobre o campo da pesquisa e sobre o que especificamente desenvolvo este artigo. Portanto, na sequencia, vou dividi-lo em subseções. Estas terão relação com as questões de realização da pesquisa destacadas acima.

Ao final da escrita, destaca-se a possibilidade de uma pesquisa produzida no encontro com as crianças, não tomada como definida a priori e afastando-se da ideia de verificação de hipóteses, apontando assim como as decisões com relação aos métodos de aproximação e de produção de dados, são produzidos a partir de um modo de perceber as crianças. Neste caso, como potentes na sua relação com o mundo.

\section{Sobre as decisões metodológicas de uma pesquisa com as crianças}

Nesta seção, trato de descrever e analisar como certas posturas com relação ao método desenvolvido ao longo de minha investigação, traçam um pararelo com o referencial teórico, que dá corpo as análises desenvolvidas a partir da produção de dados.

Optei por dividir esta parte em subseções, como já destaquei na introdução. Assim, primeiramente abordo sobre o uso dos termos de consentimento. Na sequência, trato do uso das imagens das crianças e como isso também tem relação com a proposta de consentimento e o dimensionamento ético. Após, abordo como tratei com as crianças da escolha dos nomes para identificação na escrita da dissertação, o que envolve proteção e participação. A seguir, e por último, focando especialmente sobre as características da escuta e da participação, abordo como a fotografia e o caderno de campo, além de instrumentos para a produção dos dados, serviram de suporte para a aproximação ao contexto da pesquisa e para a produção de um espaço participativo para as contribuições e investigações das crianças. Com isto, seguimos.

\subsection{Os consentimentos}

A postura que adotei na investigação desenvolvida trata de produção de dados e não de "coleta" de dados. Ou seja, os dados não estavam lá, desde sempre. Foi o encontro de minhas curiosidades e interesses com o campo da pesquisa e as crianças, que possibilitaram a construção dos dados a partir de uma pergunta bem particular. Como adulta-pesquisadora, me coloquei como "um adulto [...] que se interessa por elas, pelo que pensam, desenham, escrevem e narram" (BARBOSA, 2014, p. 244), e que procura estabelecer uma relação de confiança. 
Desta forma, fazer uma opção pelo consentimento das crianças, é uma atitude política, porque as percebe como sujeitos, e também ética, por entender que as crianças como potentes na sua relação com o mundo, através das suas múltiplas linguagens, manifestam interesses de participação ou mesmo de recusa. De acordo com Barbosa (2014),

Desde as primeiras normativas, as crianças foram colocadas como integrantes de grupos especiais, porém, em 1983, foi discutida e incluída a perspectiva de buscar, sempre que possível, o consentimento das crianças e dos adolescentes e não apenas dos adultos responsáveis. (p. 238).

A autora ainda continua, dizendo que as crianças, "são sujeitos que exigem proteção e cuidado mas que, paradoxalmente, possuem potência. [...] É uma micro- revolução, constituir com os pequenos uma experiência de capacidade, em vez de falta, de deficiência, como temos feito até agora". (BARBOSA, 2014, p. 244).

Com essas considerações, optei por realizar um consentimento com a escola e sua gestão, a professora regente do grupo, as famílias responsáveis pelas crianças e com as crianças. O consentimento realizado com as crianças deu-se através de uma conversa e de desenhos. Esta ocorreu, após algum tempo de convivência e que já havíamos estabelecido um vínculo de confiança. Os desenhos constituíram como uma maneira de registro do consentimento à participação a investigação. Também as crianças, em suas falas, destacaram suas percepções do que eu fazia naquele espaço, trago aqui duas falas: "Tu tira foto, grava, tira foto do que a gente está brincando." (Maxsteel, 5 anos); “Tu vai com a profe no lanche com a gente, tira foto da gente e deixa a gente tirar foto e tu brinca com a gente." (Bruna, 5 anos).

Neste primeiro momento, todas as famílias e todas as crianças haviam consentido em participar dos processos de investigação, e sobretudo aceitado minha presença na escola. Entretanto, foi através do processo de registro fotográfico que uma das crianças demonstrou, através de outras linguagens, que não a verbal e a gráfica, que não tinha exatamente consentido sobre o uso da sua imagem.

\subsection{O uso de imagens}

Começo esta subseção, com uma citação de Barbosa (2014), em que destaca a relevância dos registros visuais constituírem a divulgação da pesquisa:

Uma das funções mais importantes da pesquisa é a sua divulgação. No campo da formação de professores, as imagens feitas pelas crianças e as videogravações dos processos de investigação são instrumentos necessários para refletir sobre a prática pedagógica, para divulgar experiências e sugerir intervenções. Assim, se as pesquisas não permitirem registros audiovisuais, como poderemos transmitir os 
conhecimentos construídos nas investigações que filmes, fotos, e documentos como desenhos, produções escritas podem, com maior clareza, evidenciar? (p. 243)

Nesse sentido, entendo que há coisas que a palavra não alcança. A emoção, o gesto, a fisionomia, embora descritíveis, não alcançam o mesmo valor da imagem. Como escrevi na dissertação:

Em alguns casos, a fotografia suprime as muitas linhas que seriam necessárias para descrever a ideia de movimento, o olhar maravilhado de uma criança ou aquilo que nos toca tão profundamente que as palavras não alcançam na apresentação. Mesmo que a descrição seja densa e profunda, ainda assim, não encontrará a capacidade da fotografia de surpreender e seduzir. Em outros, a palavra cativa aquilo que na fotografia fica em silêncio. O movimento das fotografias das crianças, a descrição do encontro, da primeira impressão, as perguntas, a escrita como forma de pensamento, encontra nas palavras a possibilidade de reviver e manifestar o fascínio das emoções sentidas no corpo. (SIMÕES, 2015, p. 56-57)

Com estas escritas justifico minha opção por utilizar as fotografias como estratégia de narrativa ao longo do corpo do texto que se originou na pesquisa. Mas, especialmente quero retomar a questão do consentimento e ver como isso se relaciona com o uso das imagens.

Havia uma criança que, nos momentos em que eu estava fotografando ou registrando, ela se afastava, virava o corpo se colocando de costas, ou demonstrava com o olhar que estava incomodada. Em outros momentos, ela pedia para que eu a fotografasse ou então, me solicitava a máquina para fotografar as outras crianças. Era uma criança que conversava comigo, se aproximava. Mas tudo mudava quando passávamos aos registros fotográficos.

Por entender que o consentimento passa pelo corpo, e não estritamente por uma afirmação verbal ou escrita, entendi que esta criança não consentia sobre o uso da sua imagem ou das suas brincadeiras na investigação. Ali tinha um misto de sentimentos que por horas nos aproximava e em outros momentos, nos afastava. Embora com o consentimento dos pais sobre sua participação, tomei partido pelo desejo e consentimento da criança. De maneira que os registros nos quais ela aparecia não compuseram a investigação.

\subsection{A escolha dos nomes de identificação}

Uma outra questão, trata sobre a escolha dos nomes para identificar as crianças na escrita. De minha parte,

Entendo que devemos perceber com antenas sensíveis como as crianças interpretam e significam nossa presença no contexto: a aceitação ou o repúdio, linguagens corporais, verbais, que indicam como está sendo construída essa relação. Além disso, o tipo de pesquisa, o objetivo da investigação e inclusive uma situação de vulnerabilidade social das crianças, por exemplo, encaminharão para outras considerações sobre a real necessidade de identificação das crianças. (SIMÕES, 2015, p. 57) 
$\mathrm{Na}$ investigação que realizei, em uma conversa, disse às crianças que eu iria escrever uma história sobre elas, suas brincadeiras e a escola. Afinal, a escrita não é isso? Uma narrativa? Uma história sobre o desenvolvimento de uma problemática de pesquisa? Enfim, as crianças assim iam uma a uma, escolhendo os nomes pelos quais gostariam de ser identificadas na escrita da dissertação. O grupo ficou assim composto: Alison; Bruna; Luan; Matheus-Ben10; Maxsteel; Nicholas-Cage; Pablo; Pedro; Peter-Homem-Aranha; Rapunzel; Superman e Vitória.

Com essa escolha metodológica e ética, persegui uma ideia das crianças como sujeitos da cultura, potentes e que, como exemplifica a autora Sônia Kramer:

\begin{abstract}
Alternativas tais como usar números, mencionar as crianças pelas letras iniciais ou as primeiras letras do seu nome, [...] negava a sua condição de sujeitos, desconsiderava a sua identidade, simplesmente apagava quem eram e as relegava a um anonimato [...]. (KRAMER, 2002, p. 47).
\end{abstract}

Assim, as crianças escolheram seus nomes. Nomes fictícios e que lembram superherois, princesas, atores, ou mesmo um amigo de que gostam muito. Essa opção, desloca, de certa forma, as crianças da condição de objeto da pesquisa, e as coloca como sujeitos: elas se reconhecem e se identificam por esses nomes na escrita. Também foi no dia em que escolheram os nomes, que aquela criança que demonstrava não consentir com o uso da sua imagem, disse que não gostaria de estar nesta história. Além disso, no termo de consentimento que entreguei às famílias, eu indicava que as crianças teriam essa liberdade de escolha.

Esta escolha, foi ao algo realizada já ao final e com a seguinte proposição: "Vou escrever uma história sobre vocês, sobre o que vi aqui, sobre o que aprendi com vocês, sobre as brincadeiras, utilizando estas fotos que vocês fizeram e as fotos que eu também fiz (nós já havíamos visto juntos as fotografias). Então, eu queria saber qual nome vocês querem ter nesta história”. Então, na conversa, encontro o sentido do ato de narrar, voltar-se para o outro e com ele, construir sentidos sobre as nossas ações.

\title{
2.4. A fotografia e o caderno de campo
}

O acesso e o uso livre do caderno de campo e da máquina fotográfica permitiram as crianças expressarem os seus sentimentos, as suas ideias, seus valores, sobre o cotidiano que vivenciavam na escola. Em certo momento da pesquisa, optei por levar sempre duas máquinas fotográficas, em que uma ficava com as crianças e outra comigo. Na escrita da dissertação, mostro como as crianças iniciaram um projeto de investigação próprio, a partir da máquina 
fotográfica, basicamente sobre "como se produz uma fotografia?”, explorando luz/sombra e o movimento/pausa.

Essas duas estratégias fizeram com que as crianças me integrassem em suas rotinas diárias, e sempre me convidando a estar junto delas. Em algumas situações ouvi das crianças: “Olha... mas não conta pra professora tá? Senão eu fico sentado na cadeira" e nestes momentos percebia que estabelecíamos uma relação de confiança e reciprocidade, necessárias ao processo da investigação.

A fotografia e o caderno de campo se constituíram assim como elementos de aproximação entre a pesquisadora e as crianças, unidas pelo fascínio e pela curiosidade de uma experiência relacional de descoberta sobre a relação entre adultos e crianças. Uma relação não imposta, mas construída, de parceria, de apoio. Além disso, estas duas estratégias serviam como espaço de poder de participação de registro por parte das crianças.

Com relação ao caderno de campo, destaco uma passagem da dissertação:

As crianças costumavam [...] me perguntar o que eu tinha escrito ali, pedindo para que eu lesse. Esse movimento foi muito importante por dois motivos. Primeiro, porque a confiabilidade das crianças comigo aumentava e se solidificava na medida em que percebiam que eu realmente fazia aquilo que tinha dito, qual seja: anotar tudo ou pelo menos aquilo que eu conseguia, do que estavam fazendo. Segundo, porque, em alguns momentos, as crianças puderam contar o seu olhar sobre a mesma situação. (SIMÕES, 2015, p. 62)

\section{Conclusões}

Assim, buscou-se a construção de uma investigação aberta, que ocorre no encontro, e que percebe a potência das crianças. Conclui-se que a partir as estratégias utilizadas, viabilizou-se, primeiro, o empoderamento das crianças na investigação, compondo um lugar ético de autoria e parceria com a pesquisadora, fabricando novos modos de ser e estar no mundo. Em segundo, os cuidados metodológicos permitem construir a experiência (LARROSA, 2002; 2011) como um modo de fazer e produzir pesquisa com as crianças, rompendo com uma lógica que as coloca como objetos e recolocando-as como sujeitos.

O uso de estratégias que promovam o respeito a participação das crianças nas pesquisas realizadas com elas, demonstram o desejo de construir um espaço de reciprocidade, de abertura da investigação, para que possamos nos aproximar dos contextos de pesquisa. A nova resolução sobre ética nas pesquisas em ciências humanas e sociais (CNS, Resolução ${ }^{\circ}$ 510, 2016) traz, de certa forma, a justa e necessária atenção a diferentes maneiras de consentimento, para além do escrito. Nesta investigação, entendeu-se que colocá-las no lugar 
de crianças potentes, não poderia suprimir a criação do vínculo, da confiança, que se dá por um olhar, um riso, uma aproximação.

Além disso, o uso das fotografias como uma narrativa visual compõe um discurso que dimensiona a proteção e o cuidado, mas acredita na potencialidade daquilo que imagem proporciona de compreensão e surpresa. A pesquisa assim se torna ética porque aberta e respeitosa com as crianças nas suas singularidades.

\section{Referências}

ANDRÉ, M. E. D. A. de. Etnografia da prática escolar. Campinas: Papirus, 2008.

BARBOSA, Maria Carmen Silveira. A ética na pesquisa etnográfica com crianças: primeiras problematizações. Revista Práxis educativa, vol. 9, n. 1, 2014.

BRASIL. Conselho Nacional de Saúde. Resolução nº 510, 2016.

KRAMER, Sonia. Autoria e autorização: questões éticas nas pesquisas com crianças. Cadernos de Pesquisa, São Paulo, n. 116, p. 41-59, 2002.

LARROSA, Jorge. Experiência e alteridade em educação. Revista Reflexão e Ação, Santa Cruz do Sul, v. 19, n. 2, p. 04-27, 2011.

LARROSA, Jorge. Notas sobre a experiência e o saber da experiência. Revista Brasileira de Educação, n. 19, p. 20-28, jan./abr. 2002.

SIMÕES, Eleonora. De mãos dadas com as crianças pequenas pelos espaços da escola: interações, brincadeiras e invenções. Dissertação de Mestrado. PPGEDU/UFRGS: Porto Alegre, 2015. 